\title{
Examination of relocated earthquake hypocenters in the Pamir- Hindu Kush seismic zone using 3-D plots
}

\section{S Das}

Department of Earth Sciences, University of Oxford, Oxford OX1 3PR, UK

E-mail:das@earth.ox.ac.uk

Reliably relocated earthquake hypocenters in the Pamir-Hindu Kush region for about 1700 earthquakes deeper than $50 \mathrm{~km}$, are examined using 3-D color plots. The hypocenters define an single contorted "S" shaped seismic zone, $700 \mathrm{~km}$ long and no more than $30 \mathrm{~km}$ wide and with most activity concentrated in the 100$300 \mathrm{~km}$ depth range. The main features observed are:

a) the continuous steepening of the north dipping Hindu Kush seismic zone as we move eastwards towards the Pamirs;

b) the southeast dipping Pamir seismic zone;

c) the curvature and forking of the subducting slab at depths greater than $200 \mathrm{~km}$ within the eastern part of the Hindu Kush seismic zone;

d) the very abrupt cutoff in intermediate depth seismicity at $90-110 \mathrm{~km}$ depth with no extension to shallower depths, under the Pamirs, suggesting that the slab has become decoupled from the surface deformation;

e) the unusual horizontal $\mathrm{T}$-axes for intermediate depth earthquakes of the Pamir seismic zone, which align with its curvature, suggesting that this region is under horizontal compression. The study shows that the seismic zone under the Hindu Kush has stress axes which follow the classical pattern for subducting slabs controlled by gravity, whereas the Pamir region has horizontal T-axes that follow the trend of the contorted seismic zone. We suggest that the Pamir seismic zone is a remnant slab has been completely overturned and torn away from the Hindu Kush slab, to be in the current south dipping geometry, as a result of flow in the upper mantle. The 3-D plots will be shown as computer animations at the conference. 